should be available, with nursing staff trained for such an eventuality. It must be emphasized that the hospital is not the only provision for this sort of patient and fortunately many voluntary agencies provide a similar service. My own view is that the wider the spectrum of services available, the more likely the patient through his general practitioner is to get help appropriate to his need.

\section{Personal Care}

When the personal care of the individual is concerned there are three issues. The first is that the correct diagnosis must be made -in other words, if the patient is being treated as if he were dying then in fact he must be dying. In many instances clear-cut presentation is there-there is no doubt that the individual has reached the end of his life-but there are patients on whom a label of a certain illness is placed and on occasion this may be wrong, so it is essential that the physician seeing a patient for the first time with a diagnosis already fixed should review this with care and detail to satisfy himself about the diagnosis.

The second consideration is the relief of pain, and other worrying symptoms, and great attention must be paid to the minor complaints of individuals who are reckoned to be in their last illness, and Dr. Saunders ${ }^{3}$ has always stressed these points. In fact, once the diagnosis has been established, that the patient is indeed dying, the therapy, though requiring review and alteration, must nonetheless be thorough. Time must be found to talk with such patients, to listen to their complaints, worries, and requests. Their symptoms must be treated, adequate fluid intake ensured, bowel regulation without discomfort achieved, electrolyte imbalance corrected. These procedures are not directed to dragging out a life already lost, but to the complete necessity for rendering the individual comfortable, and here the nurses require the doctor's guidance. They require advice on clinical day-to-day management, and they need encouragement and sustenance to their own mental health, which may be in some risk because of the nursing of such people. For the young nurse there may be a high degree of emotional involvement and she may require detailed and kindly explanation as to why the individual whom she likes and nurses is unable to get well. She may also require explanation about measures which are being undertaken which she thinks, albeit wrongly, are prolonging the patient's life unnecessarily.

Cramond ${ }^{1}$ believed that, when there is a very close relationship between patient and doctor, the doctor should give the patient a lead-in, in that he may be able to express his worries and doubt and to ask questions whether in fact he is dying. He stressed the need for training of personnel with regard to this situation. If, bearing in mind a full consideration of the patient's physical and psychological make-up and his best interests, it has been agreed that there should be a conspiracy of silence, then without consultation no well-meaning friend or relative should take it on himself or herself to tell the patient the whole truth, with the patient being unprepared, unexpecting, and unwanting to receive $s_{i}$ th information. For staff education we require training and explanation of each stage of therapy. We need to instruct our staff in the ability to communicate with relatives, visitors, and the clergy, and we need to encourage an enthusiastic outlook on pain-relieving therapy, and vigilance in the detection of discomfort and distressing symptoms.

\section{Support for the Bereaved}

The best person to give immediate comfort for those bereaved is almost certainly the family doctor, acting in co-operation and with the help of the priest or clergy if this is desired. Studying the effect of bereavement on elderly people as a health visitor, Wilson postulated that this is a time when a continuing contact with a skilled visitor such as the health visitor is of the utmost importance. After bereavement the older person generally tends to withdraw from friends and society. Wilson thinks that a most effective method of preventing social isolation and loneliness in old people is through support given at the time of greatest grief, encouraging the intake of adequate diet, and ensuring that they do not become completely cut-off from their families, friends, and neighbours, and that some interest is found for them. She felt that there should be a list kept of elderly people living together, so that if one became ill a watch could be kept; if bereavement occurred health visiting of the remaining elderly person would take care immediately. Numerous studies have shown the deleterious effect of bereavement on older people's mental health.

Time is the great healer, but during this hard phase of life every effort must be made to prevent a turning away from everyday matters and the feeling of hopeless depression.

\section{References}

1 Cramond, W. A., British Medical fournal, 1970, 3, 389.

2 Gibson, R., Fournal of the Royal College of Physicians of London, 1971, 5, 135.

3 Saunders, C., Proceedings of the Royal Society of Medicine, 1963, 56, 195. 4 Wilson, F. G., Lancet, 1970, 2, 1356.

\section{University of Glasgow}

W. FERGUSON ANDERSON, O.B.E., M.D., F.R.C.P., David Cargill Professor of Geriatric Medicine

\section{Where to Die}

\section{E. WILKES}

I am fond of saying that the two commonest diagnoses in general practice are the fear of life and the fear of death, and that, surprisingly and rather pathetically, the fear of life is the more common. The fear of death and the fear of dying can be a heavy, indeed a disabling, burden. This is natural; one cannot separate society from the medicine that serves that society. And our society has an uncertain and insecure attitude to death and to dying because we are a world removed from the farm-yard realities of birth and life and death. Indeed, in one survey only $15 \%$ of medical professional workers in training had, before their training, ever seen anyone die. And this partly is what all the fuss is about. The reasons for this are of course social. We have changed the causes of death, the type of dying, the place of dying, and the age of dying. Naturally, therefore, the medical and nursing professions, despite their centuries of involvement in these sorts of problems, are feeling somewhat inadequate and in need of a reassessment of their role and of the situation.

In my own practice we found that no less than $68 \%$ of deaths were consequent on a slow and tedious illness which on purely clinical grounds we classed as overdue. And in a society in which small houses and the part-time job are part of the pattern of life, this obviously produced special stress and special strain. The place of dying is therefore not unconnected with the problems of the terminal illness, and we have seen a great expansion in this country of dying in an institution. In my own area a few years ago we found that $55 \%$ of cancer deaths occurred at home, but about a third died in an acute hospital bed and about $10 \%$ in the long-stay geriatric units. We are obviously getting towards the New York State situation, where less than a quarter of all deaths occur at home. Moreover, of the half million deaths each year in the British Isles half take place at over 75 years of age, over 90,000 at over 85 years of age, and over 500 at over 100 years of age. So the magnitude as well as 
the novelty of the problem naturally enough are somewhat daunting.

This situation does give rise to problems obviously relevant. For example, of our cancer survey in the scheduled areas we found that no less than $14 \%$ of cancer patients dying at home were being looked after by relatives, themselves aged over $\mathbf{7 0}$ years. And this is a problem that is not going to get better. We expect in the next decade that those over 65 in the population will increase by $12 \%$ and those over 75 in the next decade will increase by $18 \%$. So in this situation the natural history of dying at home is of some interest. In a survey done through general practitioners (over $90 \%$ of whom completed their forms for us) something like half of cancer patients dying at home had no significant pain, no suffering, and no distress. Something like a third of patients dying of cancer at home had problems, but for less than six weeks. Those who had problems for over six weeks were on average something like $15 \%$ of cases. Those that made heavy demands on the G.P. were something like $12 \%$ of cases, and those that needed hospital care-extra facilities that they could not otherwise get-were something like $17 \%$ of cases. Thus the problem is a minority one from the point of view of the doctor and the nurse, though not of the family. We must never become crude and insensitive, buffeted as we are by the recurrent problems of the day, but we must bear in mind that we are dealing today with the unfulfilled needs and the deplorable neglect of something like $10 \%$ or $15 \%$ only.

\section{The Sheffield Unit}

Our small eccentric unit in Sheffield, with which I am associated, is only a faint shadow of the St Christopher's Hospice, but it does demonstrate the possibility of what can be done without leadership of the quality of Dr. Cicely Saunders. It also has very individual, and I think important, qualities of its own. Firstly, we accept in this unit the importance of the relatives, and every member of staff from the stewards to the senior nurses are taught to treat relatives very much as our guests and as part of the team. Indeed if we have an 80-year-old husband, as we have had, devotedly caring for his dying wife until he could go on no longer and living at some distance away with difficult travelling, we admitted them both. This is very simple as long as you are not a National Health Service hospital.

Although our main interest is in the needs and care of the dying, it is not exclusively so. We are also taking a few postoperative convalescent holiday patients and other types of case, so that we are attaining a discharge rate of something like $20 \%$ from our unit. In breast cancer we are attaining a discharge rate of no less than $25 \%$; this is also true of rectal carcinoma, because if we can get these patients early to control their symptoms we like to send them home, where quite often they manage and do not come back. However, we have never fewer than two or three readmissions on our wards and they are all greeted as old friends coming home. This I think is very important.

We have people of all ages in our wards, from the teens to the 90 s, and the majority have been brought up in a tradition of work, a slightly embarrassing and out-of-date tradition. If they cannot work because they are ill their day loses savour and dignity, and therefore we have an occupational therapist with voluntary assistants of a high order; although 96 of our first 300 patients were dead within a week of admission, never less than a quarter of our patients were usefully and actively involved in occupational therapy-and the work is very good.

Another thing that is important is the integration of relatives into the volunteer system. We are a small unit of 25 beds on the edge of a provincial city, but we have something between 250 and 300 volunteers. Some of them do only a morning every fortnight. Most do rather more than that, and they vary, of course, tremendously in their expertise and the skills they have to offer. Some are principal nursing officers, some health visitors, some just housewives, and some rather elderly and frail ones. But even the tea bar made $£ 400$ in a year, and this is of very great value when one is dealing with a private charity and a contractual bed arrangement with the regional board slanted slightly but inevitably in favour of the regional board. The presence of these volunteers has been an important factor in the maintenance of staff morale, although we are in the slightly extraordinary situation of having a waiting list for nurses. One of the important aspects of the volunteers' contribution is that they form a beautician, manicurist, hairdresser, and chiropody unit. This has been found to be of tremendous therapeutic importance.

\section{Role of Special Units}

The contribution of these special units-of which there are obviously more than St. Christopher's and St. Luke's-is not that we are necessarily dedicated or clever, but that we are small.

When all is said and done, however, it is a nursing unit and the nursing must be of the highest possible calibre. I have been most impressed by the maturing process that one has seen going on in theological students due to be ordained in a few months who have been working as nursing auxiliaries for a few weeks on our wards. They have received a tremendous lot from the patients and given something to the patients. Now we are becoming a teaching unit for nurses, and we have had doctors and medical students of all sorts of grades and seniority working as nursing auxiliaries on the wards. We have attained a standardization of technique which means that any of our nursing auxiliaries can take a senior registrar or a senior medial student and make him do it the right way. This is of course decades overdue, and is slightly depressing that an individual private charity should be the first one to do this. I think, however, that this work is extremely important. It is the only mechanism I can see whereby young doctors can acquire some background, training, and experience to assess the comfort of their patient, to assess the standard of nursing care-and this can, at times, be deplorable not because nurses are worse than 15 years ago but because they are very often in shorter supply. This is no criticism of the nursing profession; it is merely a criticism of the society in which they work.

It is very important in a unit especially involved in the care of the dying not to take anything for granted. One lady referred to us from a very good hospital was a paraplegic consequent on a mammary carcinoma and secondary deposits. With the help of our physiotherapist she became mobile and not only went home, but lived alone for quite a few months before she relapsed.

Anniversaries are terribly important to us. The whole ward is turned upside down when there is a silver wedding or a golden wedding or a birthday. The event has a peculiarly individual significance if it happens to be your last birthday. Similarly we have not only routine services in the chapel but a few weeks ago we had our first christening in the chapel, and this merely demonstrates the importance of family life in difficult circumstances. The more difficult the circumstances the more important the maintenance of family relationships. Given suitable encouragement and support, patients and relatives have an amazing courage and dignity, although we tend grossly to underestimate this because they have not the capacity to manipulate words. Because of this there must be somewhere, somehow, a unit that will take anything in its stride, that will never be dismayed, that will never be disgusted, but that will always whenever it is permitted be emotionally involved. This is possible if you have the staffing in acute units, if you have the beds. At the moment I would have thought you have not, and you will not get them in the short term. Therefore there is need for special units with this close to their hearts, and perhaps I might allay one or two fears of the general practitioners if $I$ end by saying that in our unit the general practitioner is encouraged to look after his own patients.

University of Sheffield and St. Luke's Nursing Home, Shefiield

ERIC WILKES, M.R.C.P., M.R.C.G.P., Professor of Community Care and Medical Director. 